\title{
SYNTHESIS AND CHARACTERIZATION OF (THIO)CARBAMATES BASED
}

\section{ON CELLULOSE AND CELLULOSE ACETATE:}

\author{
BIODEGRADATION AND SOLUBILITY STUDIES
}

\author{
FATIMA EZAHRA TABAGHT, ${ }^{*}$ ABDERRAHMANE EL IDRISSI, ${ }^{*}$ MOHAMED AQIL,** \\ ABDESSAMAD BENAHEMAD, ${ }^{*}$ SOUFIAN EL BARKANY, ${ }^{* * *}$ REDA BELLAOUCHI $^{* * * *}$ and \\ ABDESLAM ASEHRAOU ${ }^{* * * *}$ \\ *Laboratory of Applied Chemistry and Environment, Faculty of Sciences, Mohammed First University, \\ Oujda 60000, Morocco \\ ${ }^{* *}$ Materials Science and Nano-Engineering, Mohammed VI Polytechnic University (UM6P), \\ Lot 660 Hay Moulay Rachid, Ben Guerir, Morocco \\ ${ }^{* * *}$ Laboratory of Applied Chemistry and Environment, Multidisciplinary Faculty, \\ Mohammed First University, Nador 62000, Morocco \\ ${ }^{* * *}$ Laboratory of Biochemistry and Biotechnology, Faculty of Sciences, Mohammed First University, \\ Oujda 60000, Morocco \\ Corresponding author: F. E. Tabaght, f.tabaght@ump.ac.ma
}

Received May 18, 2019

In this work, a facile method was developed to modify cellulose and cellulose acetate fibers by an approach that consists in converting the hydroxyl groups existing on their surfaces to carbamate, using 1,6-hexamethylene diisocyanate (HDI) as a connecting agent. Firstly, a precursor with a free isocyanate end group was prepared and thereafter it was used for a homogeneous one-pot modification of these raw materials, avoiding toxic solvents and expensive reagents. The obtained derivatives were characterized using FTIR, NMR, TGA/DTG and XRD techniques. The study of their solubility allowed determining the values of the solubility parameters ( $\delta \mathrm{i})$, the values of the solventpolymer interaction parameters $\left(\chi_{\mathrm{s}-\mathrm{p}}\right)$; therefore, their solvent systems. The biodegradability of cellulose and its derivatives was investigated under aerobic conditions in solid conditions and liquid medium. The results indicated that these raw materials are biodegradable and can substitute currently used industrial non-biodegradable products. They can have some applications in different industrial fields, such as adsorbents, food packaging and antibacterial materials, respecting the protection of the environment. A sustainable development and an increased use of green chemistry principles are among the essential objectives of this work.

Keywords: cellulose derivatives, click chemistry, solubility behavior, biodegradation conditions

\section{INTRODUCTION}

Cellulose is the most abundant renewable biopolymer on the earth, ${ }^{1}$ possessing several important properties, for example, it is inexhaustible and low cost, it has low density and abrasiveness, as well as high specific strength and modulus, it is non-toxic and biocompatible, it requires low energy consumption, etc. ${ }^{2}$ It is a carbohydrate polymer constructed from repeating $\beta$-D-glucopyranose units. ${ }^{3}$ Cellulose fibers are widely used to enhance the physico-chemical properties of composites with variable morphologies and at modest cost. ${ }^{4,5}$ In addition, their biodegradation and biocompatibility make them very promising over other fibers, broadening their fields of industrial applications. Indeed, cellulosic fibers and their derivatives are used in many fields, such as food, paper, clothes, healthcare products and membranes. ${ }^{6}$

Cellulose derivatives are used in a broad field of applications, for example, cellulose acetate (CA) is used in photographic films, ${ }^{7}$ surface coatings, ${ }^{8}$ membranes in various separation processes, ${ }^{9}$ cigarette filters, textile fibers, etc. ${ }^{10}$ Cellulose acetate is the most important ester of cellulose, which is obtained using the acetylating reaction. ${ }^{11,12}$ It possesses, in contrast to cellulose, 
a less crystalline structure and thus exhibits better solubility in common organic solvents, such as acetone. ${ }^{13}$ Moreover, the solubility of cellulose acetate depends, among other things, on the degree of substitution (DS), hydrogen bonding and the interaction parameter between cellulose acetate and the solvent $\left(\chi_{\mathrm{ps}}\right)^{14}$

Carbamate compounds based on cellulose derivatives may be useful alternatives to replace petroleum-based polymers, and their synthesis has been the subject of many scientific works, indicating that this family occupies a large area of scientific research. ${ }^{15,16}$ In general, cellulose carbamates are synthesized by reacting the cellulose esters with the carbamate acids (carbamic acid), or by combining urea and cellulose at an elevated temperature. ${ }^{17}$ Besides, Yin et al. showed that supercritical conditions can be another synthesis procedure, using a supercritical carbon dioxide solution containing the urea. ${ }^{18,19}$ These conventional processes require a long time, high temperature, catalysts and organic solvents. Another modification method for cellulose fibers using isocyanate groups was developed and was the subject of numerous studies. ${ }^{20-22}$ Urethane groups are formed easily, accompanied with several advantages, namely, high reaction rates, absence of by-products and chemical stability. ${ }^{22}$ In addition, other studies have reported a method using microwave heating under catalyst-free conditions as an eco-friendly process for synthesizing cellulose thiocarbamate. ${ }^{17,23}$

"Thiocarbamate" is the generic name given to the species with the general formula $\mathrm{R}_{1} \mathrm{SC}(\mathrm{O}) \mathrm{NR}_{2} \mathrm{R}_{3}$ or $\mathrm{R}_{1} \mathrm{OC}(\mathrm{S}) \mathrm{NR}_{2} \mathrm{R}_{3}{ }^{24}$ Similarly to the carbamate, they have been applied in various commodity chemicals, such as herbicide, pesticide, bactericide and antiviral agents. ${ }^{15}$ Cellulose thiocarbamates can be also obtained by heating cellulose with thiourea at $180^{\circ} \mathrm{C}$. $^{25,26}$

Generally, several modification reactions of cellulose are carried out in a heterogeneous medium. Recently, the researchers have focused their attention on the improvement of homogeneous methods in order to modify cellulose, because more uniform and stable products could be obtained in homogeneous medium. ${ }^{27}$ In addition, the discovery of novel solvents and solution complexes for cellulose in the past three decades has created some opportunities for using significantly more diverse synthesis pathways. ${ }^{28}$ Moreover, to the best of our knowledge, derivatization (carbamate and 208 thiocarbamate) is carried out under heterogeneous conditions. However, the chemical modification of cellulose and cellulose acetate derived from Esparto, using diisocyanate as a connecting agent, has not been widely studied and detailed systematically, hence, the rationale of this work.

In this study, we performed the synthesis of cellulose carbamate and cellulose acetate carbamate using cellulose fibers extracted from Esparto grass (Stipa tenacissima) growing in Eastern Morocco. These novel derivatives can be more soluble in different solvent systems at low temperature, offering at the same time compatibility and biodegradability properties. A blocked isocyanate as a coupling agent was employed to reach these compounds containing carbamate and thiocarbamate groups simultaneously under homogeneous conditions. This grafting method allows controlling easily the degree of substitution (DS) or the density of the graft. The obtained derivatives were characterized by Fourier transform infrared (FTIR) and nuclear magnetic resonance (NMR) spectroscopy techniques. Their structures were also evaluated using X-ray diffraction (XRD) and thermal analysis (TGA/DTG), and their solubility behavior was also investigated. Furthermore, this procedure using a sustainable raw material was conducted in a one-pot process, avoiding harmful reagents and respecting some principles of green chemistry. In this work, cellulose fibers, cellulose acetate and their novel derivatives (Cell-HDIthiol and CA-HDI-thiol) were investigated with the aim of determining the extent of their biodegradability in two different biodegradation environments (solid condition and liquid medium). The effect of the chemical modification on the biodegradation kinetics was also determined.

\section{EXPERIMENTAL}

\section{Material and instrumentation}

Cellulose $\left(\mathrm{DP}_{\mathrm{w}}=1400\right.$ and $\left.\mathrm{M}_{\mathrm{w}}=227200 \mathrm{~g} / \mathrm{mol}\right)$ was extracted from Esparto grass (Stipa tenacissima), growing in Eastern Morocco, following the procedure developed by El Idrissi et al. ${ }^{29}$ It was dried in a vacuum oven at $90{ }^{\circ} \mathrm{C}$ for $48 \mathrm{~h}$ before use. Dibutyltindilaurate (DBTL 95\%) was obtained from Aldrich and used as a catalyst. Lithium chloride ( $\mathrm{LiCl}$ 98\%) was obtained from Riedel-de Haën Company. Dichloromethane, methanol, N,N-dimethyl acetamide (DMAc), 1,6-hexamethylene diisocyanate (HDI 98\%) and 1-dodecanethiol $(\geq 98 \%)$ were purchased from Sigma-Aldrich. All other chemicals were purchased 
from Sigma-Aldrich. The chemicals were of analytical grade and used without further purification.

FTIR experiments were performed using a Shimadzu FTIR 8400S Fourier Transform Infrared spectrometer, using $\mathrm{KBr}$ discs containing $2 \%$ of finely ground samples. Twenty scans were taken of each sample recorded from 4000 to $400 \mathrm{~cm}^{-1}$. The FTIR spectra were accumulated at a resolution of $4 \mathrm{~cm}^{-1}$.

The NMR spectra were recorded in UATARS, National Center for Scientific and Technical Research (CRNST) (Rabat, Morocco), using an AVANCE Bruker $300 \mathrm{MHz}$ spectrometer at 294.8 K. Deuterated dimethyl sulfoxide (DMSO- $\mathrm{d}_{6}$ ) was used as solvent. All spectra were recorded after 16 scans, with a pulse delay of $20 \mathrm{~s}$.

Thermal behaviors were determined using a Q500 TGA Thermogravimetric Analyzer from TA instruments, at a heating rate of $20{ }^{\circ} \mathrm{C} \mathrm{min}^{-1}$, under a $50 \mathrm{~mL} \mathrm{m^{-1 }}$ nitrogen flow, within the range from 25 to $600{ }^{\circ} \mathrm{C}$.

X-ray diffraction (XRD) was performed using a diffractometer system (Shimdza XRD 6000) with $\mathrm{Cu}$ $(\lambda=0.154 \AA$ ) (Oujda, Morocco).

\section{Preparation of cellulose and cellulose acetate carbamates \\ Extraction of cellulose \\ Cellulose $\left(\mathrm{DP}_{\mathrm{w}}=1400\right.$ and $\left.\mathrm{M}_{\mathrm{w}}=227200 \mathrm{~g} / \mathrm{mol}\right)$} was extracted from Esparto (Stipa tenacissima), growing in Eastern Morocco, following the procedure developed by El Idrissi et al. ${ }^{29}$ Briefly, the fibers of Esparto were ground into fine particles and then were treated with $\mathrm{NaOH}$ solution at $80{ }^{\circ} \mathrm{C}$ for $2 \mathrm{~h}$, with mechanical stirring (3 times) using $\mathrm{HClO}_{4}$ as catalyst. After each treatment, the fibers were filtered and washed twice with a bleaching agent $(\mathrm{NaClO})$, then several times with distilled water and finally with ethanol and diethyl ether. Finally, the bleaching of the fibers is done with mechanical stirring 4 times at $80^{\circ} \mathrm{C}$ for 4 hours. The resulted product was heated at $105^{\circ} \mathrm{C}$ until constant weight was reached, and dried over phosphorus pentoxide in desiccators.

\section{Preparation of cellulose solution}

According to the procedure of El Idrissi et al., ${ }^{29}$ in a three-necked round-bottom flask equipped with a thermometer, a magnetic stirrer and a reflux condenser, $0.292 \mathrm{~g}$ of cellulose and $25 \mathrm{~mL}$ of DMAc were placed. The mixture was heated at $150{ }^{\circ} \mathrm{C}$ for $30 \mathrm{~min}$, then cooled to $100{ }^{\circ} \mathrm{C}$ and then $9 \%$ (3 g) of $\mathrm{LiCl}$ was added. The mixture was again stirred at $50{ }^{\circ} \mathrm{C}$ for $15 \mathrm{~h}$. Finally, a clear cellulose solution was obtained.

\section{Preparation of cellulose carbamate (Cell-HDI-thiol)}

In a three-necked round-bottom flask, equipped with an addition funnel, a thermometer, a magnetic stirrer and a reflux condenser, $0.4 \mathrm{~mL}(2.5 \mathrm{mmol})$ of HDI were introduced. Then, $0.6 \mathrm{~mL}(2.5 \mathrm{mmol})$ of 1dodecanethiol with a relative amount of DBTL as a catalyst, placed in the funnel, was added dropwise to the reaction mixture. The system was kept under nitrogen atmosphere at $80{ }^{\circ} \mathrm{C}$ until the end of the reaction $(3 \mathrm{~h})$. The FTIR spectrum shows the presence of an absorbance band at $2270 \mathrm{~cm}^{-1}$ assigned to the remaining free NCO group. This synthesis was realized in solvent-free conditions. Without isolating the precursor (HDI-thiol) (Fig. 1a), the cellulose solution already prepared $(0.2 \mathrm{~g})$ was added to the mixture, which was kept under stirring at $80^{\circ} \mathrm{C}$, until the absorbance band of NCO group disappeared totally. The final product (Cell-HDI-thiol) (Fig. 1b) was isolated by precipitation in a mixture of methanol/water $(1 \mathrm{v} / 3 \mathrm{v})$, filtered on a membrane filter, washed firstly with distilled water, and then with methanol, and dried under vacuum.

\section{Preparation of cellulose acetate (CA)}

Cellulose acetate was prepared according to the method described in the literature. ${ }^{30}$ Briefly, $10 \mathrm{~g}$ of cellulose powder was placed in a round bottom flask, with $80 \mathrm{~mL}$ of acetic acid, $120 \mathrm{~mL}$ of toluene and 2 $\mathrm{mL}$ of perchloric acid. The mixture was vigorously shaken for a few minutes and then $50 \mathrm{~mL}$ of acetic anhydride was added. The reaction was stopped after 10 min. Finally, cellulose acetate was isolated by precipitation in distilled water and dried overnight in an oven at $90^{\circ} \mathrm{C}$.

\section{Preparation of cellulose acetate carbamate (CA-HDI- thiol)}

In a three-necked round-bottom flask, equipped with an addition funnel, a thermometer, a magnetic stirrer and a reflux condenser, $0.4 \mathrm{~mL}(2.5 \mathrm{mmol})$ of HDI was placed. Then, an amount $(0.6 \mathrm{~mL})$ of 1 dodecanethiol with a relative amount of DBTL as a catalyst, placed in the funnel, was added dropwise to the reaction mixture. The system was kept under stirring in nitrogen atmosphere at $80{ }^{\circ} \mathrm{C}$ for $3 \mathrm{~h}$. Following the same procedure as described previously, an amount $(0.54 \mathrm{~g})$ of cellulose acetate dissolved in anhydrous dimethylsulfoxide was added slowly to the processor (HDI-thiol) mixture under stirring. The final product (CA-HDI-thiol) (Fig. 1b) was precipitated in methanol, after filtration and washing successively with distilled water and then by methanol. The final product was dried in an oven at $60^{\circ} \mathrm{C}$ for $24 \mathrm{~h}$.

\section{Solubility study \\ Theoretical study}

In this work, we describe some methods that allow the determination of solubility parameters $(\delta i)$ and behaviour.

\section{Hildebrand method}

The solubility parameter has been defined as the square root of the cohesive energy density, and describes the attractive strength between molecules in the material ${ }^{31}$ (Eq. 1): 


$$
\delta=\left(\frac{E}{V}\right)^{\frac{1}{2}}
$$

where $V$ is the molar volume of the pure solvent, and $E$ is its (measurable) energy of vaporization.

\section{Hansen method}

Hansen solubility parameters are widely used by the paint and coatings industries for selecting suitable solvents for polymeric resins.

According to the Hansen solubility parameter theory, ${ }^{32}$ the energy of vaporization can be divided into contributions of non-polar (dispersion) forces (d), polar forces (p), and hydrogen-bonding (h):

$E=E_{d}+E_{P}+E_{h}$

The solubility parameter is presented in the following form:

$$
\delta^{2}=\delta_{d}^{2}+\delta_{p}^{2}+\delta_{h}^{2}
$$

where $\delta_{\mathrm{d}}{ }^{2}-$ the contribution of dispersion forces; $\delta_{\mathrm{p}}{ }^{2}-$ the contribution of polar forces; $\delta_{\mathrm{h}}{ }^{2}-$ the contribution of hydrogen bonding.

\section{Hoftyzer and Van Krevelen method}

The solubility parameter components may be predicted from group contributions, using the following equations: ${ }^{33}$

$$
\begin{aligned}
& \delta_{d}=\frac{\sum F_{d i}}{V} \\
& \delta_{p}=\frac{\sqrt{\sum F_{p i}^{2}}}{V} \\
& \delta_{d}=\sqrt{\frac{\sum E_{h i}}{V}}
\end{aligned}
$$

\section{Calculation of the solvents parameter interaction}

According to the regular solution theory, the relationship between the Flory-Huggins interaction parameter and the solubility parameters is:

$\chi_{S P}=\frac{V_{S}}{R T}\left(\delta_{S}-\delta_{P}\right)^{2}$

where Vs is the molar volume of the solvent, $\delta_{s}$ and $\delta_{p}$ are the Hildebrand solubility parameters for the solvent and polymer, respectively, $R$ is the gas constant and T is the absolute temperature.

To estimate the value of $\chi_{S P}$, Hansen used the following equation (8) with $\alpha=1$ :

$\chi_{S P}=\alpha \frac{V_{S}}{R T}\left(\left(\delta_{s, d}-\delta_{P, d}\right)^{2}+0.25\left(\delta_{S, p}-\delta_{p, p}\right)^{2}+0.25\left(\delta_{S, h}-\delta_{p, h}\right)^{2}\right)$

Lindvig et al. ${ }^{34}$ have estimated the value of the FloryHuggins interaction parameters from the Hansen parameters, with an optimum value of the correction constant $\propto=0.6$. As mentioned, the correction constant was different for different species pairs. According to the Flory-Huggins model, a polymer and solvent are completely miscible if $\chi_{S P}<0.5\left(1+\sqrt{V_{m s} / V_{m p}}\right)^{2} \approx 0.5$.

\section{Solubility tests}

Some dissolution tests of the cellulose derivatives obtained were carried out by the following procedure. In the first step, powder samples were placed in a small weighing bottle and dried in a vacuum oven at $70{ }^{\circ} \mathrm{C}$. In a second step, the dried samples $(1 \mathrm{mg})$ were placed in a bottle with an adequate solvent $(0.1 \mathrm{~mL})$ at room temperature, for the carbamate of cellulose acetate, and at $120{ }^{\circ} \mathrm{C}$ for other samples. The mixture was kept under stirring until the powder disappeared (visual monitoring) and transparent solutions were obtained in DMSO for cellulose carbamate and cellulose acetate carbamate, respectively, and in dichloromethane for cellulose acetate carbamate (Table 1).

\section{Biodegradability test methods}

There are several different methods and techniques to determine the biodegradability of plastic materials under different conditions (laboratory or field conditions). In this work, we have focused on visual observation and on the quantitative determination of microbial growth when cellulose derivatives were submitted to biodegradation and used as carbon source. This test was established in two steps. The first one was based on the visual observation of the crossroads of the microorganisms (solid medium). The second one was the biodegradability process following the standard test method ISO 14851.

\section{Biodegradation under aerobic solid conditions}

This test method was standardized and adopted basically in the same form by the American Society for Testing and Materials (ASTM G21-70, G22-76, G2975 ), by the French Association for normalization (AFNOR X 41-514-81 and X41-517-69), by the German Institute of Standardization (DIN 53739) and by the International Organization for Standardization (ISO 846). ${ }^{35}$ The tested biopolymers were placed on the surface of a solid culture medium $\left(\mathrm{M}_{\mathrm{S}}\right)$ as a sole carbon source in the medium. The solid culture medium $\left(\mathrm{M}_{\mathrm{S}}\right)$ is composed of monopotassium phosphate $\left(\mathrm{KH}_{2} \mathrm{PO}_{4}: 0.7 \mathrm{~g}\right)$, potassium hydrogen phosphate $\left(\mathrm{K}_{2} \mathrm{HPO}_{4}: 0.7 \mathrm{~g}\right)$, magnesium sulfate heptahydrate $\left(\mathrm{MgSO}_{4} / 7 \mathrm{H}_{2} \mathrm{O}: 0.7 \mathrm{~g}\right)$, ammonium nitrate $\left(\mathrm{NH}_{4} \mathrm{NO}_{3}: 1 \mathrm{~g}\right)$, sodium chloride $(\mathrm{NaCl}: 0.005 \mathrm{~g})$, ferrous sulfate heptahydrate $\left(\mathrm{FeSO}_{4} / 7 \mathrm{H}_{2} \mathrm{O}: 0.002 \mathrm{~g}\right)$, zinc sulfate heptahydrate $\left(\mathrm{ZnSO}_{4} / 7 \mathrm{H}_{2} \mathrm{O}: 0.002 \mathrm{~g}\right)$ and manganese sulfate heptahydrate $\left(\mathrm{MnSO}_{4} / 7 \mathrm{H}_{2} \mathrm{O}: 0.001\right.$ g) dissolved in sufficient distilled water to make up $1000 \mathrm{~mL}$ with agar (autoclaving at $121^{\circ} \mathrm{C}$ for $20 \mathrm{~min}$, $\mathrm{pH}$ was between 6.0 and 6.5) in a Petri dish containing no additional carbon source. The tested biopolymers and the agar medium were sprayed with standardized mixed inoculums of lixivia. Petri dishes were 
incubated at a constant temperature for 21 to 28 days. The tested biopolymers were then subjected to visual assessment.

\section{Biodegradation under aerobic liquid conditions}

The assessment of biodegradability was performed following the standard test method ISO $14851 .^{36}$ Glass flasks with a $600 \mathrm{~mL}$ capacity were used as test vessels. The flasks were filled till a final $400 \mathrm{~mL}$ volume and kept closed with glass caps. The test liquid medium was the "standard test medium" described in ISO 14851 (Determination of the ultimate aerobic biodegradability of plastic materials in an aqueous medium-method by measuring the oxygen demand in a closed respirometer), based on the following solutions:

- Solution A: $\mathrm{KH}_{2} \mathrm{PO}_{4}(8.5 \mathrm{~g} / \mathrm{L}), \mathrm{K}_{2} \mathrm{HPO}_{4}$ $(21.75 \mathrm{~g} / \mathrm{L}), \mathrm{Na}_{2} \mathrm{HPO}_{4} \cdot 2 \mathrm{H}_{2} \mathrm{O}(33.4 \mathrm{~g} / \mathrm{L}), \mathrm{NH}_{4} \mathrm{Cl}(0.5$ $\mathrm{g} / \mathrm{L})$;

- $\quad$ Solution B: $\mathrm{MgSO}_{4} \cdot 7 \mathrm{H}_{2} \mathrm{O}(22.5 \mathrm{~g} / \mathrm{L})$;

- Solution C: $\mathrm{CaCl}_{2} \cdot 2 \mathrm{H}_{2} \mathrm{O}(36.4 \mathrm{~g} / \mathrm{L})$;

- Solution D: $\mathrm{FeCl}_{3} \cdot 6 \mathrm{H}_{2} \mathrm{O}(0.25 \mathrm{~g} / \mathrm{L})$.

The test medium was prepared by adding $10 \mathrm{~mL}$ of solution A, and $1 \mathrm{~mL}$ of each of solutions B, C, and D to about $500 \mathrm{~mL}$ of water and bringing the volume to $1000 \mathrm{~mL}$ with water. The inoculum solution was prepared as follows. A sample was drawn from the soil, diluted with water in order to reach a final concentration of $200 \mathrm{~g} / \mathrm{L}$, and aerated for $4 \mathrm{~h}$. Each vessel was filled with $380 \mathrm{~mL}$ of test medium and inoculated with $20 \mathrm{~mL}$ of inoculum solution. Test or reference material was added to each vessel $(50 \mathrm{mg})$, with the exception of the blanks. Two replicates were used for each material and for the blanks. The tests were stopped when $\mathrm{O}_{2}$ consumption was no longer detectable, in all cases at least after three months. The Oxitop system used in the determination of BOD contains an individual number of reactors, consisting of glass bottles with a carbon dioxide trap (sodium hydroxide) in the headspace. The bottles are supplied with a magnetic stirrer and sealed with a cap containing an electronic pressure indicator.

Afterwards, each vessel was kept under aeration for 15 min to restore the original oxygen concentration of the liquid medium. The vessels were then closed and put back in incubation. The net biochemical oxygen demand (BOD) of the tested biopolymers was calculated as the difference between the oxygen consumption in the test and in the blank flasks using Equation $9:^{37}$

net $\mathrm{BOD}=\mathrm{BOD}_{\mathrm{tm}}-\mathrm{BOD}_{\mathrm{b}}$

where $\mathrm{BOD}_{\mathrm{tm}}$ is the total biochemical oxygen demand of the tested biopolymers from one flask; $\mathrm{BOD}_{\mathrm{b}}$ is the biochemical oxygen demand of the blanks (average of two flasks).

The percentage of biodegradation $\mathrm{D}_{\mathrm{tm}}$ is calculated as the ratio of the net biochemical oxygen demand to the total theoretical oxygen demand (total ThOD, referred to the amount of tested biopolymers introduced originally in the flask) using Equation 10:

$$
\mathrm{D}_{\mathrm{tm}}=\frac{\text { net BOD }}{\text { total ThOD }} \times 100
$$

where $\mathrm{D}_{\mathrm{tm}}$ - percentage of biodegradation; net BOD specific biochemical oxygen demand (in $\mathrm{mg} \mathrm{O}_{2} / \mathrm{L}$ ); ThOD - theoretical oxygen demand (in $\mathrm{mg} \mathrm{O}_{2} / \mathrm{g}$ ).

The ThOD of the polymer $n\left(\mathrm{C}_{\mathrm{c}} \mathrm{H}_{\mathrm{h}} \mathrm{O}_{\mathrm{o}} \mathrm{N}_{\mathrm{n}} \mathrm{S}_{\mathrm{s}}\right)$, with a relative molecular mass $\mathrm{Mr}$ (per monomer), was calculated according to Equation $11:^{38}$

ThOD $=\frac{31.9988(\mathrm{c}+0.25(\mathrm{~h}-3 \mathrm{n})+1.5 \mathrm{~s}-0.5 \mathrm{o})}{\mathrm{M}_{\mathrm{r}}}$

The experiments were stopped when no further oxygen consumption was detectable and were repeated twice.

\section{RESULTS AND DISCUSSION Synthesis}

In the first stage, we extracted cellulose fibers form Esparto grass (Stipa tenacissima), following the procedure developed by El Idrissi et al. ${ }^{29}$ This product was already characterized by different spectroscopy techniques (FTIR, NMR, etc.) and its molecular weight was evaluated by the viscosimetry method $(\mathrm{DP}=1402$ and $\mathrm{Mw}=$ 227200). ${ }^{29}$ In the second stage, we prepared cellulose acetate according to the method described in the literature by Doyle and Pethrick. ${ }^{30}$ Its substitution degree (DS = 1.7) was calculated using the NMR technique.

In the third stage, the preparation of cellulose thiocarbamate and cellulose acetate thiocarbamate was discussed. The modification was conducted by a classical addition reaction, using the isocyanate group as a coupling agent. Firstly, a precursor (noted HDI-thiol) was synthesized by reacting one of the functional groups of the 1,6(HDI) with the end group $(-\mathrm{SH})$ of the dodecanethiol (Fig. 1a), using DBTL as catalyst in order to prepare a compound having an isocyanate group at its chain end (R-S-OC-HN$\left.\left(\mathrm{CH}_{2}\right)_{6}-\mathrm{NCO}\right)$. Lastly, the remainder isocyanate group on the precursor was reacted with the hydroxy groups of the cellulose backbone or on the cellulose acetate backbone, using the grafting onto technique, as described in Figure 1b. This synthesis was realized homogeneously as a onepot process. The protection of the environment and the development of green chemistry are the main objectives.

\section{FTIR analysis}

The cellulose FTIR spectrum (Fig. 2a) shows a large absorption band at $3396 \mathrm{~cm}^{-1}$ characterizing 
the stretching vibration of the hydroxyl groups. The band situated at $2899 \mathrm{~cm}^{-1}$ is associated with the stretching vibration of $-\mathrm{CH}-/-\mathrm{CH}_{2}-$ and the absorption band at $1647 \mathrm{~cm}^{-1}$ corresponds to naturally absorbed water. The spectrum also shows absorption bands around $1431 \mathrm{~cm}^{-1}$ and $1373 \mathrm{~cm}^{-1}$, characterizing the deformation vibrations of - $\mathrm{CH}-$ and - $\mathrm{OH}$, respectively. Furthermore, the peak at $1058 \mathrm{~cm}^{-1}$ is assigned to the C-O-C stretching vibration, whereas the absorption band at $895 \mathrm{~cm}^{-1}$ is a characteristic of the beta-glucidic bond. ${ }^{39}$

In the FTIR spectrum of the Cell-HDI-thiol (Fig. 2a), the stretching vibration band of the $\mathrm{C}=\mathrm{O}$ urethane group (-NHCO-O-) is wrapped by a new absorption peak at $1637 \mathrm{~cm}^{-1}$, assigned to the carbamate group -NHCO-S-. Moreover, a new absorption band characterizing the -NHCO-Ourethane appeared at $3329 \mathrm{~cm}^{-1}$. This indicates that the precursor (HDI-thiol) was grafted to cellulose, leading to cellulose thiocarbamate derivatives. The bands stemming from blocked isocyanate situated at 2856 and $2929 \mathrm{~cm}^{-1}$ broadened due to the addition of $-\mathrm{CH}-/-\mathrm{CH}_{2}-$. In addition, the intensity of the absorbance of hydroxyl groups at 3200-3500 $\mathrm{cm}^{-1}$ decreased and disappeared with an increase in the nitrogen content, which caused a decrease of the hydrogen bonding density in the cellulose chains. ${ }^{40}$ The grafting phenomenon was also confirmed by an obvious absorption peak at $1577 \mathrm{~cm}^{-1}$, assigned to the bending vibration of the $\mathrm{N}-\mathrm{H}$ bond.

The FTIR spectrum of cellulose acetate (Fig. 2b) shows an absorption band located at 1750 $\mathrm{cm}^{-1}$, assigned to the $\mathrm{C}=\mathrm{O}$ stretching vibration of the ester group $\left(-\mathrm{CH}_{2} \mathrm{C}=\mathrm{O}\right)$. It is worth noting that this spectrum shows a decrease in the absorption intensity of the band located around $3431 \mathrm{~cm}^{-1}$ assigned to the stretching of the hydroxyl groups, compared with the cellulose spectrum. This decrease occurs because hydroxyl groups are substituted by acetyl ones. ${ }^{41}$

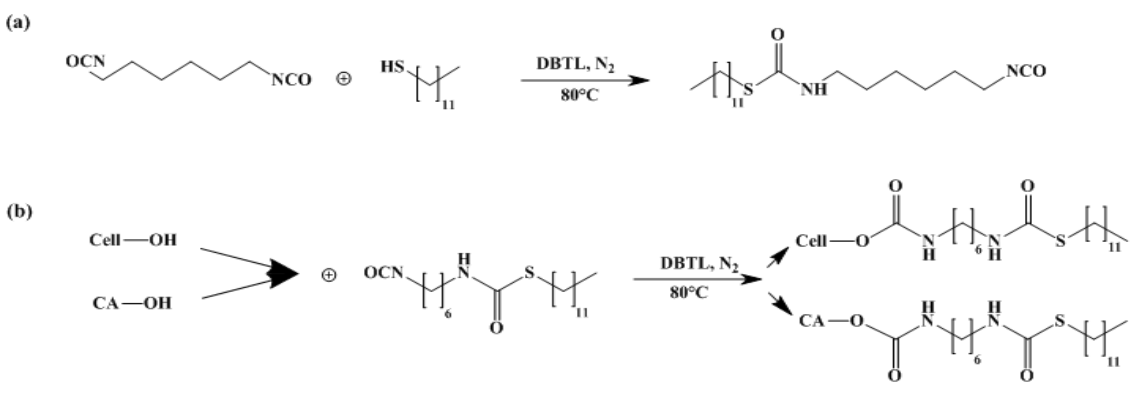

Figure 1: Preparation of (a) HDI-thiol precursor, and (b) cellulose and cellulose acetate carbamate

(a)

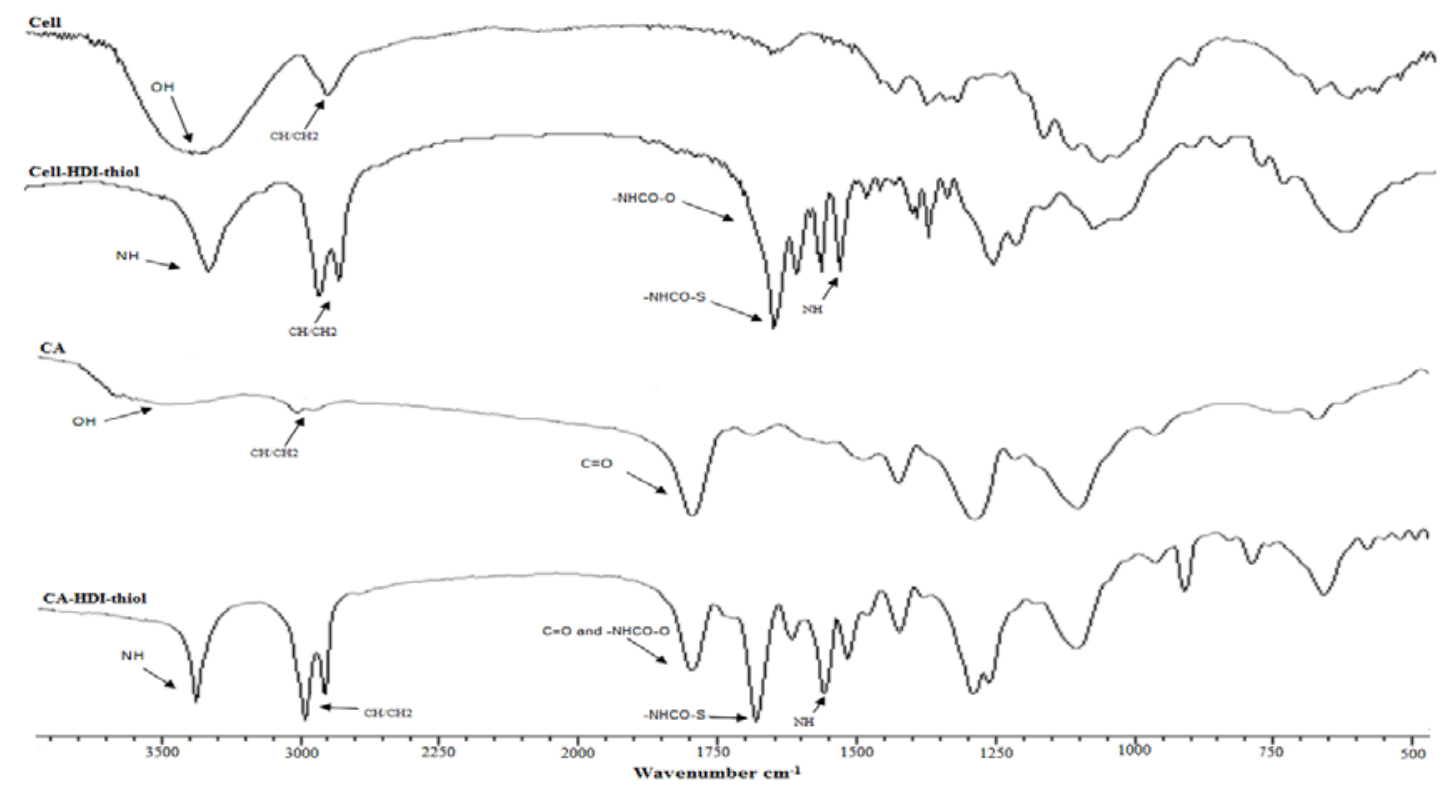

Figure 2: FT-IR spectra of (a) Cell, (b) Cell-HDI-thiol, (c) cellulose acetate and (d) CA-HDI-thiol 
The cellulose acetate thiocarbamate (CA-HDIthiol) shows several new absorption bands in its FTIR spectrum (Fig. 2b). A new absorption band at $1637 \mathrm{~cm}^{-1}$ is assigned to the stretching vibration of thiocarbamate carbonyl (-NHCO-S-). The absorption band located at $1753 \mathrm{~cm}^{-1}$ is assigned to the $\mathrm{C}=\mathrm{O}$ stretching vibration of the ester group $\left(\mathrm{CH}_{3} \mathrm{CO}-\mathrm{O}-\right)$ and wrapped the vibration band of the $-\mathrm{C}=\mathrm{O}$ urethane group (-NHCO-O-). The increase in the absorption bands intensity at 2852 and $2924 \mathrm{~cm}^{-1}$ is assigned to the stretching vibration of -CH-/- $\mathrm{CH}_{2}$ - groups (addition of $-\mathrm{CH}-$ $/-\mathrm{CH}_{2}-$ ). The absorption band appearing at 3327 $\mathrm{cm}^{-1}$ is assigned to the -NHCO-O- stretching vibration of the urethane. The formation of the thiocarbamate groups was confirmed by the disappearance of the absorption bands attributed to the hydroxyl and isocyanate groups around 3500 and $2270 \mathrm{~cm}^{-1}$, respectively. This modification was also confirmed by an obvious absorption band at $1512 \mathrm{~cm}^{-1}$, assigned to the bending vibration of the N-H bond. The FTIR spectrum of CA-HDI-thiol shows clearly that all the hydroxyl groups have been reacted.

\section{NMR analysis}

The NMR spectra of the cellulose and cellulose derivatives (Cell-HDI-thiol/CA-HDIthiol) are in accordance with the proposed structures. Indeed, the ${ }^{1} \mathrm{H}$ NMR spectra of CellHDI-thiol and CA-HDI-thiol are presented in Figure 3. The proton signals existing between 2.8 and $5.6 \mathrm{ppm}$ are attributed to the cellulose skeleton. The peaks situated in the areas of 0.8$1.88 \mathrm{ppm}$ and $3.03-3.33 \mathrm{ppm}$ are assigned to the methylene protons $\left(-\mathrm{CH}_{2}-\right)$ of (1, 6-HDI-thiol) compound. The signals (a, b and c) and (h, g, f, e and d) are attributed, respectively, to HDI and dodecanethiol methylenes. In addition, the proton signals of the amide group $(-\mathrm{NH}-\mathrm{C}=\mathrm{O})$ appeared at 8.01 (i) and $6.8 \mathrm{ppm}$ (j) for Cell-HDI-thiol (Fig. 3a) and at 6.02 (j) and 8 ppm (i) for CA-HDI-thiol (Fig. 3b).

The protons signal of the cellulose acetate backbone appears between 2.5 and $5.5 \mathrm{ppm}$ for CA-HDI-thiol. These results are in agreement with those published previously by El Barkany et $a l .{ }^{21}$ We have used the ${ }^{1} \mathrm{H}$ NMR technique to estimate the degree of substitution (DS) of cellulose acetate, cellulose thiocarbamate and cellulose acetate thiocarbamate using Equation $12:^{42}$

$$
\mathrm{DS}=\frac{n_{A U G} * I_{i}}{n_{i} * I_{A U G}}
$$

where $I_{i}$ - integration of the grafted group (i); $\mathrm{I}_{\mathrm{AGU}}$ - integration of the cellulose skeleton; $\mathrm{n}_{\mathrm{AGU}}$ and $n_{i}$ - number of protons in cellulose or cellulose acetate $\left(\mathrm{n}_{\mathrm{AGU}}=7\right)$ and in the corresponding grafted group, respectively.

$$
\begin{aligned}
& D S_{\text {Cell-HDI-thiol }}=\frac{7 I_{N H}}{2 I_{A U G(C)}}=\frac{7 * 1.57}{2 * 5.63}=0.97 \\
& D S_{C A}=\frac{7 I_{C H 3}}{3 I_{A U G(C A)}}=\frac{7 * 34.53}{3 * 47.63}=1.69 \approx 1.7 \\
& D S_{C A-H D I-\text { thiol }}=\frac{7 I_{C H 3}}{3 I_{A U G(C A)}} * \mathrm{DS}_{\mathrm{CA}}=\frac{7 * 1.48}{3 * 5.05} * 1.7=1.16
\end{aligned}
$$

It should be noted that the total DS of the derivative CA-HDI-thiol is equal to 2.86 (DS = $1.7+1.16$ ) and it is slightly larger than the DS of the derivative Cell-HDI-thiol. To increase considerably the DS of these derivatives, it is necessary to introduce more equivalents of the precursor.

The ${ }^{13} \mathrm{C}$ NMR spectra of the compounds CellHDI-thiol and CA-HDI-thiol (Fig. 4) show some characteristic signals situated between 11 and 43 ppm, which are typically attributed to aliphatic carbons and could be considered as an indication justifying the attachment of aliphatic groups at the main chain of cellulose fibers. The signals characterizing the carbonyl groups are around 160 and $170 \mathrm{ppm}$ corresponding to the amide carbonyl group $(-\mathrm{NH}-\mathrm{C}=\mathrm{O})$ and to the thio carbonyl group $(-\mathrm{S}-\mathrm{C}=\mathrm{O})$, respectively, for Cell-HDI-thiol and for CA-HDI-thiol.

Furthermore, the signal characterizing the ester carbonyl group of cellulose acetate appeared at $159 \mathrm{ppm}$. In addition, the signals of the cellulose backbone appear from 72.4 to $77 \mathrm{ppm}$ for Cell-HDI-thiol and from 72 to $76.5 \mathrm{ppm}$ for CA-HDI-thiol, respectively. These results are in accordance with those already reported in the literature. $^{43}$

\section{TGA/DTG analysis}

Figures $5 \mathrm{a}$ and $5 \mathrm{~b}$ illustrate the thermograms of the thermal decomposition (TGA/DTG) of both compounds (cellulose and Cell-HDI-thiol). It is worth noticing that cellulose fibers (Fig. 5a) are decomposed in two steps. The first weight loss is observed between 20 and $220{ }^{\circ} \mathrm{C}$, resulting from elimination of the solvents and, especially, residual water, having some interactions with the main cellulosic chain. 
The second step is the major decomposition for pristine cellulose and proceeded from 220 to $400{ }^{\circ} \mathrm{C}$, with the maximum decomposition temperature appearing around $367^{\circ} \mathrm{C}$. The main residues (about 6\%) are attributed to the formation of char, which are easily volatilized. The results of this study were also confirmed by the literature. ${ }^{44}$ For the Cell-HDI-thiol derivative (Fig. 5a), after the first loss of moisture and the desorption of gases between $100-150{ }^{\circ} \mathrm{C}$, the second weight loss occurs between $150{ }^{\circ} \mathrm{C}$ and $290^{\circ} \mathrm{C}$. It is attributed to the decomposition of the grafted chains and represents around $30 \%$ of the total weight. The major decomposition observed in temperature range of $290-410{ }^{\circ} \mathrm{C}$ is mainly attributed to the thermal decomposition of the cellulosic skeleton. The first thermal degradation temperature $\left(\mathrm{T}_{\mathrm{i}}\right)$ shifted from $370{ }^{\circ} \mathrm{C}$ for cellulose (Cell) to $290{ }^{\circ} \mathrm{C}$ for Cell-HDI-thiol. This slight decrease can be explained by the disappearance of the hydrogen bonds existing between the cellulose chains, the rupture of these bonds involves some energy.

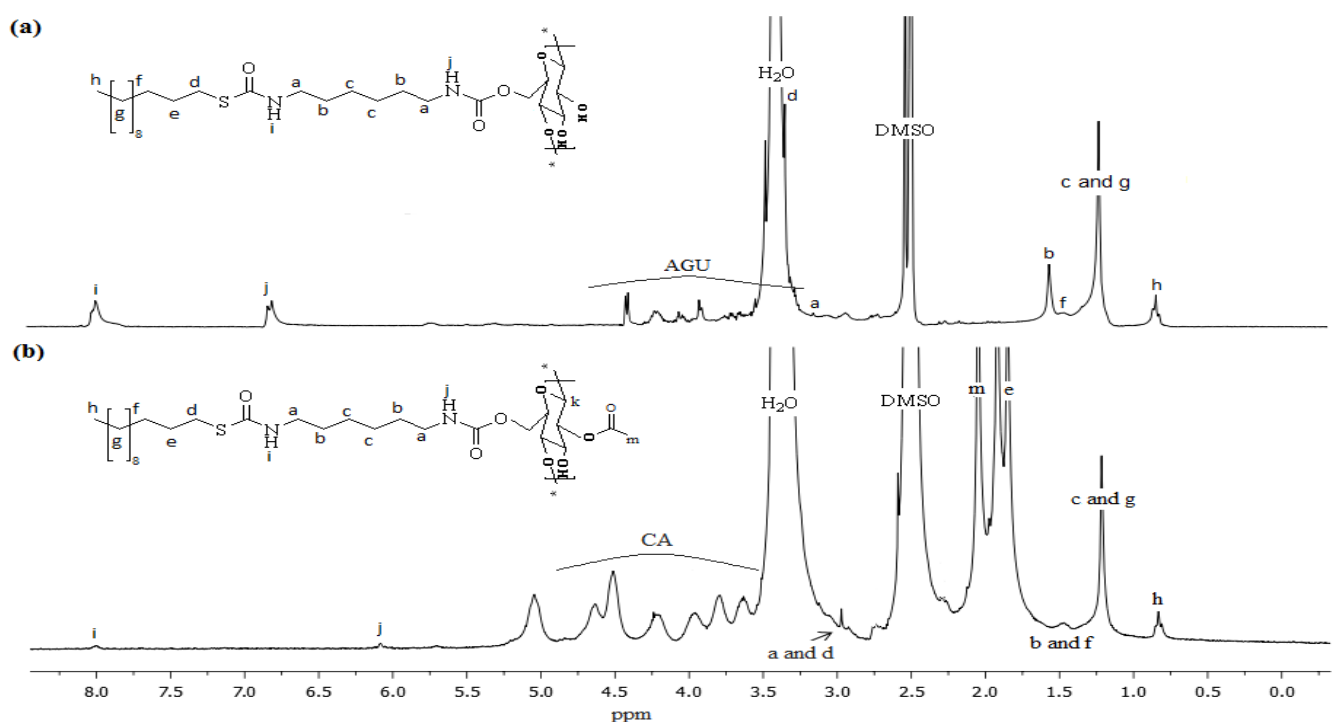

Figure 3: ${ }^{1} \mathrm{H}$ NMR spectra of (a) Cell-HDI-thiol and (b) CA-HDI-thiol
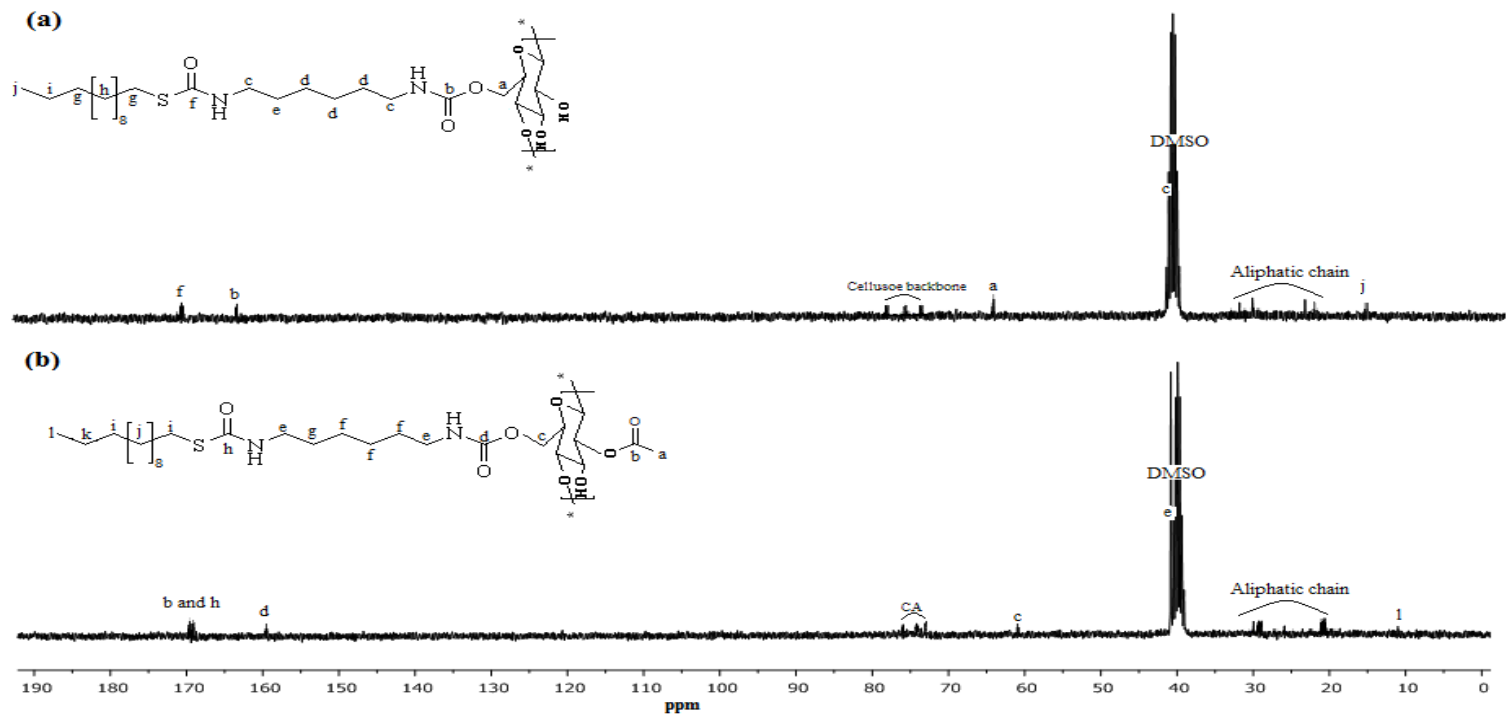

Figure 4: ${ }^{13} \mathrm{C}$ NMR of (a) Cell-HDI-thiol and (b) CA-HDI-thiol 
(a)

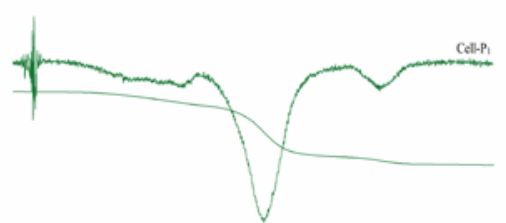

(b)

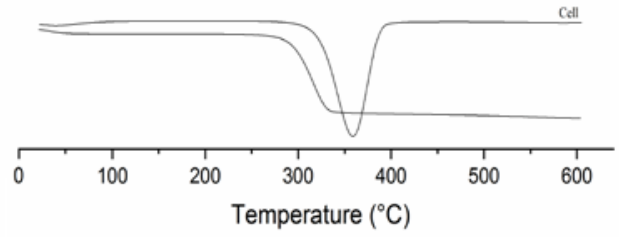

(c)

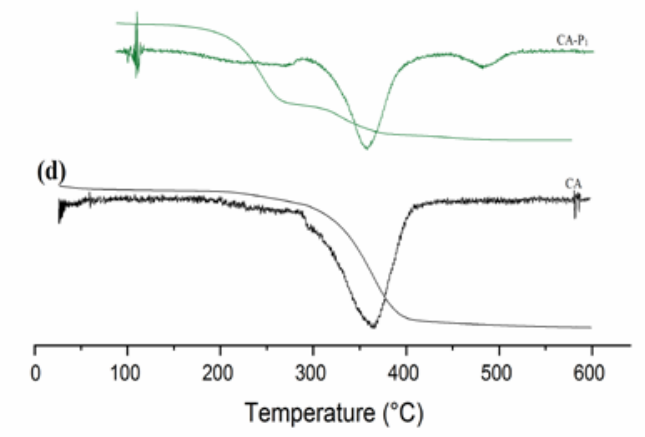

Figure 5: TGA/DTG thermograms of (a) Cell- $\mathrm{P}_{1}$, (b) Cell, (c) CA- $\mathrm{P}_{1}$ and (d) CA

The second step is confirmed by an intense endothermic peak in Figure 5b with a mass loss of $60 \%$, its maximum appearing around $350^{\circ} \mathrm{C}$. The last step is observed at $410{ }^{\circ} \mathrm{C}$ with a $4.4 \%$ mass loss. The temperature of $410^{\circ} \mathrm{C}$ is the limit of the degradation process, showing that thermal degradation is complete for cellulose and CellHDI-thiol, respectively.

In the case of cellulose acetate, the thermal decomposition occurred in three steps (Fig. 5c). The first one is before $190{ }^{\circ} \mathrm{C}$ and represents the volatilization of residual absorbed water. The second step is framed between $190{ }^{\circ} \mathrm{C}$ and 400 ${ }^{\circ} \mathrm{C}$, and represents the thermal degradation of the cellulose acetate main chain. The third step starts at $400{ }^{\circ} \mathrm{C}$ and may be attributed to the ash formation.
The TGA and DTG curves of the CA-HDIthiol derivative show three slopes of weight loss. The first step occurs from 150 to $280{ }^{\circ} \mathrm{C}$, representing the degradation of all grafted groups (acetyl ant HDI-thiol) and has a maximum at about $257^{\circ} \mathrm{C}$, with a mass loss of $53.54 \%$ (Fig. $5 \mathrm{~d}$ ). The second one is situated between 280 and $400{ }^{\circ} \mathrm{C}$, and represents the decomposition of the main cellulosic chain. This step also possesses a maximum at $337^{\circ} \mathrm{C}$ (Fig. 5d). The final one starts at $400{ }^{\circ} \mathrm{C}$, with a slight weight loss practically negligible. It can be noted that the derivatives Cell-HDI-thiol and CA-HDI-thiol are less stable than their counterparts (cellulose and CA), probably due to the cleavage of the thiocarbamate groups.

Table 1

$\mathrm{F}_{\mathrm{d}}, \mathrm{F}_{\mathrm{p}}, \mathrm{E}_{\mathrm{h}}{ }^{*}$ and number of Groups i present in the chemical formula of Cell-HDI-Thiol and CA-HDI-Thiol derivatives

\begin{tabular}{ccccccc}
\hline Group i & $\begin{array}{c}\mathrm{F}_{\mathrm{d}} \\
\left(\mathrm{j}^{1 / 2} \mathrm{~cm}^{3 / 2} \mathrm{~mol}^{-1}\right)\end{array}$ & $\begin{array}{c}\mathrm{F}_{\mathrm{p}}^{2} \\
\left(\mathrm{j} \mathrm{cm}^{3} \mathrm{~mol}^{-1}\right)\end{array}$ & $\begin{array}{c}\mathrm{E}_{\mathrm{h}} \\
\left(\mathrm{j} \mathrm{mol}^{-1}\right)\end{array}$ & $\begin{array}{c}\text { Molar } \\
\text { volumes } \\
\left(\mathrm{cm}^{3} \mathrm{~mol}^{-1}\right)\end{array}$ & $\begin{array}{c}\text { Cell-HDI-thiol } \\
(\mathrm{DS}=0.97)\end{array}$ & $\begin{array}{c}\text { CA-HDI-thiol } \\
(\mathrm{DS}=1.16)\end{array}$ \\
\hline$-\mathrm{COO}-$ & 390 & 240100 & 7000 & 18 & 00.97 & 01.16 \\
$\mathrm{CH}_{3}$ & 420 & 00 & 00 & 33.5 & 00.97 & 02.86 \\
$\mathrm{CH}_{2}$ & 270 & 00 & 00 & 16.1 & 18.46 & 21.88 \\
$\mathrm{CH}$ & 80 & 00 & 00 & -1 & 05.00 & 05.00 \\
$\mathrm{OH}$ & 210 & 250000 & 20000 & 10 & 02.30 & 00.14 \\
$-\mathrm{O}-$ & 100 & 160000 & 3000 & 3.8 & 02.00 & 02.00 \\
$\mathrm{NH}$ & 160 & 44100 & 3100 & 4.5 & 01.94 & 02.34 \\
$-\mathrm{S}-$ & 440 & - & - & 12 & 00.97 & 01.16 \\
$-\mathrm{CO}-$ & 290 & 592900 & 2000 & 10.8 & 00.97 & 02.86 \\
$\mathrm{Ring}$ & 190 & - & - & 16 & 01.00 & 01.00 \\
\hline
\end{tabular}

${ }^{*} \mathrm{~F}_{\mathrm{d}}$ - dispersion component giving $\delta_{\mathrm{d}}, \mathrm{F}_{\mathrm{p}}-$ polar component, $\mathrm{E}_{\mathrm{h}}-$ contribution of hydrogen bond forces to the cohesive energy of group i 


\section{Solubility study}

The solubility study aims to determine the Flory-Huggins interaction parameters $\left(\chi_{\mathrm{sp}}\right)$ from Hansen partial solubility parameters (HSP), calculated using the Van Krevlen-Hoftyze (VKH) method and the approximation of Lindvig.

Cellulose and its derivatives are quite polar molecules, with several -OH groups, and thus show good hydrogen bonding ability. The insolubility of cellulose and its derivatives is due to their ability to form intra- and intermolecular hydrogen bonds. ${ }^{45}$ The solubility of cellulose acetate depends on its degree of substitution. ${ }^{14}$ The application of the Van Krevlen-Hoftyze (VKH) group contribution method successively using Equations 6, 7 and 8 and the contribution of each group given in Table 1 allow the calculation of the partial solubility parameters.

The theoretical values are provided by the group contribution method, using the approximate molar volume described by Lindvig et al. ${ }^{34}$ Table 2 summarizes the values of the Flory-Huggins interaction parameter $\left(\chi_{s p}\right)$ between the solvent (S) and the thiocarbamate products (Cell-HDI-thiol and CA-HDI-thiol). The experimental solubility tests of Cell-HDI-thiol and CA-HDI-thiol were carried out as described in the experimental part. Some solvents were tested, keeping the mixture under stirring until all the powder disappeared (visual monitoring). The solubility of these derivatives shows that their dissolving power depends on the polymer and solvent nature, respectively. The tests were used as a basis for evaluating the influence of the nature and density of the graft moieties on the dissolution behavior.

Theoretically, the solubility could be achieved in ethanol, chloroform, dichloromethane and THF for the Cell-HDI-thiol derivative; and in acetone, chloroform, dichloromethane, toluene and THF for the CA-HDI-thiol derivative. On the other hand, the results of the tests realized experimentally are not fully in contradiction with those obtained theoretically. The solubility could not occur in ethanol, but it could in DMSO, DMAc and chloroform, as well as in dichloromethane for Cell-HDI-thiol. Furthermore, in the case of CA-HDI-thiol, the solubility was observed in DMSO, DMF, chloroform and dichloromethane, but not in acetone, toluene and THF. This difference between the theoretical and experimental results is probably caused by the existence of inter- and intramolecular hydrogen bonds, which make the solubility more difficult, or by theoretical calculation errors or experimental ones. The effect of temperature must be taken into account during this study as well. Generally, it can be concluded that the introduction of thiocarbamate groups on the cellulose and cellulose acetate backbones enhances their solubility behaviour.

\section{XRD analysis}

XRD results show some important information about the grafted reactions and the lattice of cellulose and cellulose acetate. The XRD patterns of the cellulose, Cell-HDI-thiol, cellulose acetate and CA-HDI-thiol are presented in Figure 6. It can be seen that cellulose has $2 \theta$ diffraction peaks at $13.82^{\circ}, 16.30^{\circ}, 22.04$ and $34.10^{\circ}$, justifying the typical cellulose I crystalline form. ${ }^{19}$ Furthermore, the XRD pattern of the Cell-HDI-thiol derivative (Fig. 6b) displays some new peaks around $2 \theta=$ $11^{\circ}, 22.88^{\circ}, 23.78^{\circ}, 24.89^{\circ}$ and $26.15^{\circ}$, showing the presence of new crystal planes, indicating that the grafting process was successful and a change has occurred in the morphology of cellulose. The cellulose acetate presents a lower degree of crystallinity (63\%), compared to the cellulose (88\%), due to the substitution of the hydroxyl groups by acetyl groups, partially the inter- and intra-molecular hydrogen bonds were eliminated. ${ }^{46}$ The XRD pattern of the neat cellulose acetate in Figure 6c shows diffuse peaks around $2 \theta=8.05^{\circ}, 19.74^{\circ}, 20.75^{\circ}, 22.75^{\circ}, 24.09^{\circ}$ and $26.76^{\circ}$, and two maxima at $2 \theta=17^{\circ}$ and at $24^{\circ}$, indicating the presence of a semi-crystalline behavior. ${ }^{41,47}$ The main peak located at approximately $8.05^{\circ}$ was cited as the principal indication of the semi-crystalline behavior of cellulose acetate. ${ }^{41}$ To estimate the state order in Cell-HDI-thiol and CA-HDI-thiol, the crystallinity index (CrI) was calculated using Equation (13): ${ }^{48}$

$$
\operatorname{CrI}(\%)=\frac{I_{002}-I_{a m}}{I_{002}} * 100
$$

where $\mathrm{I}_{002}$ is the maximum intensity (in arbitrary units) of the 002 lattice diffraction and $\mathrm{I}_{\mathrm{am}}$ is the intensity of diffraction in the same units at $2 \theta=18^{\circ}$. 
Table 2

Flory-Huggins interaction parameter values $\left(\chi_{\mathrm{sp}}\right)$, and solubility test results for Cell-HDI-thiol and CA-HDI-thiol

\begin{tabular}{|c|c|c|c|c|c|c|c|c|}
\hline \multirow{3}{*}{ Solvents } & & \multirow{3}{*}{$\mathrm{V}_{\mathrm{m}}$} & \multirow{3}{*}{$\begin{array}{c}\begin{array}{c}\text { Cell-HDI-thiol } \\
\text { (DS=0.97) }\end{array} \\
\chi_{\mathrm{sp}}\end{array}$} & \multirow{3}{*}{$\begin{array}{c}\text { CA-HDI-thiol } \\
(\mathrm{DS}=1.16) \\
\chi_{\mathrm{sp}}\end{array}$} & \multicolumn{4}{|c|}{ Solubility behavior } \\
\hline & & & & & \multicolumn{2}{|c|}{ Theoretical solubility } & \multicolumn{2}{|c|}{ Experimental solubility } \\
\hline & & & & & Cell-HDI-thiol & CA-HDI-thiol & Cell-HDI-thiol & CA-HDI-thiol \\
\hline \multirow{3}{*}{$\begin{array}{l}\text { Polar protic } \\
\text { solvents }\end{array}$} & Ethanol & 58.40 & 00.50 & 00.81 & \pm & - & - & - \\
\hline & Methanol & 40.40 & 00.66 & 00.96 & - & - & - & - \\
\hline & Water & 18.00 & 01.31 & 01.70 & - & - & - & - \\
\hline \multirow{5}{*}{$\begin{array}{l}\text { Polar aprotic } \\
\text { solvents }\end{array}$} & DMSO & 71.00 & 00.86 & 00.90 & - & - & + & + \\
\hline & DMF & 77.00 & 00.64 & 00.70 & - & - & - & \pm \\
\hline & DMAc & 93.00 & 00.60 & 00.58 & - & - & \pm & - \\
\hline & Acetone & 73.30 & 00.67 & 00.46 & - & + & - & - \\
\hline & Acetonitrile & 52.40 & 01.12 & 00.95 & - & - & - & - \\
\hline \multirow{6}{*}{$\begin{array}{l}\text { Non-polar } \\
\text { aprotic } \\
\text { solvents }\end{array}$} & Chloroform & 79.70 & 00.29 & 00.02 & + & + & \pm & \pm \\
\hline & Dichloromethane & 63.60 & 00.23 & 00.06 & + & + & \pm & + \\
\hline & Toluene & 106.3 & 00.85 & 00.22 & - & + & - & - \\
\hline & Hexane & 130.5 & 02.11 & 01.00 & - & - & - & - \\
\hline & THF & 81.20 & 00.27 & 00.11 & + & + & - & - \\
\hline & Diethyl ether & 103.9 & 00.50 & 01.13 & - & - & - & - \\
\hline
\end{tabular}

+: Soluble, \pm : Partly soluble, -: insoluble

${ }^{*} \mathrm{~V}_{\mathrm{m}}$ is molar volume, $\chi_{\mathrm{sp}}$ is Flory-Huggins interaction parameter between the solvents and the biopolymers (Cell-HDI-thiol, CA-HDI-thiol) 


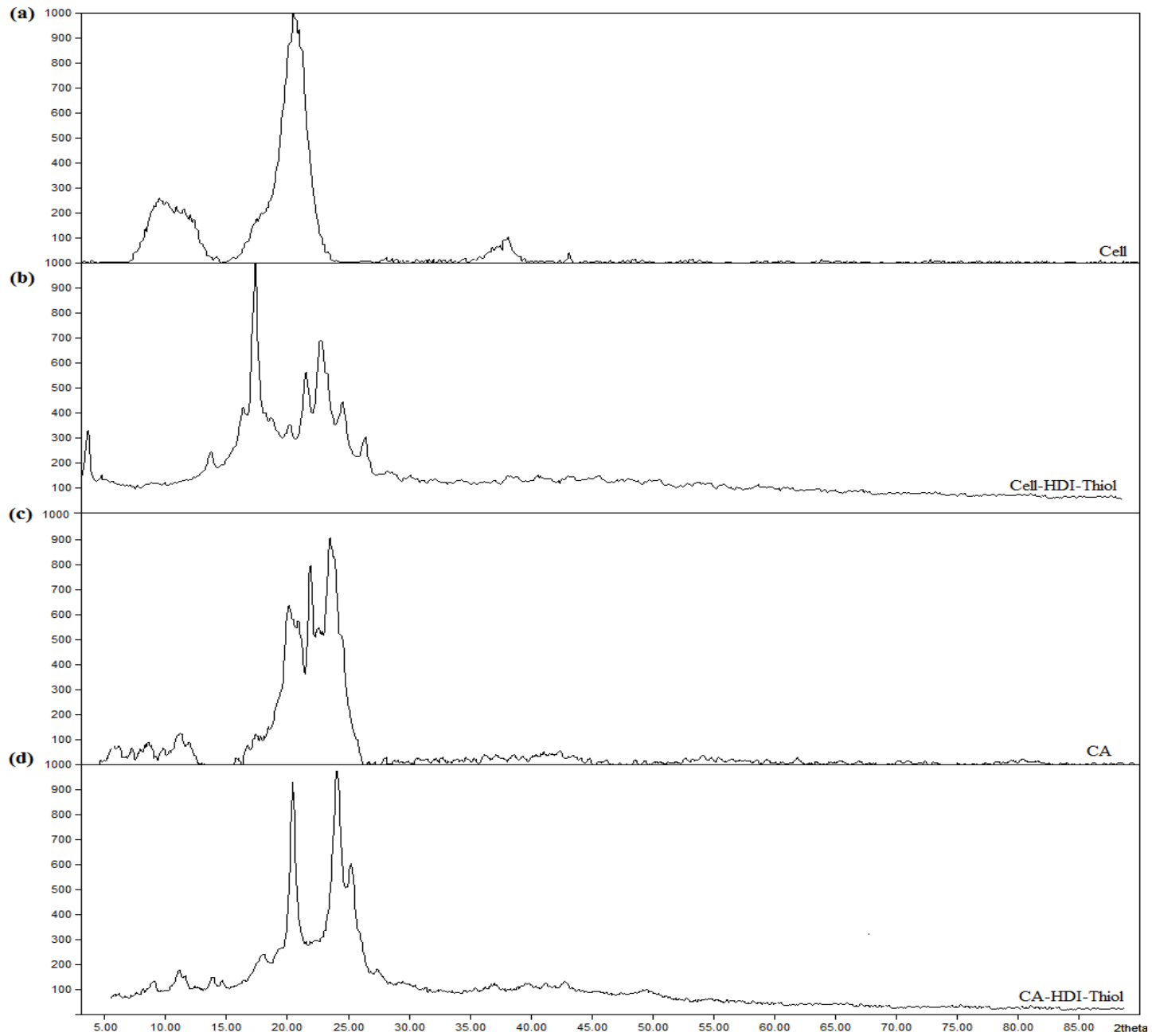

Figure 6: XRD patterns of (a) cellulose, (b) Cell-HDI-thiol, (c) cellulose acetate and (d) CA-HDI-thiol

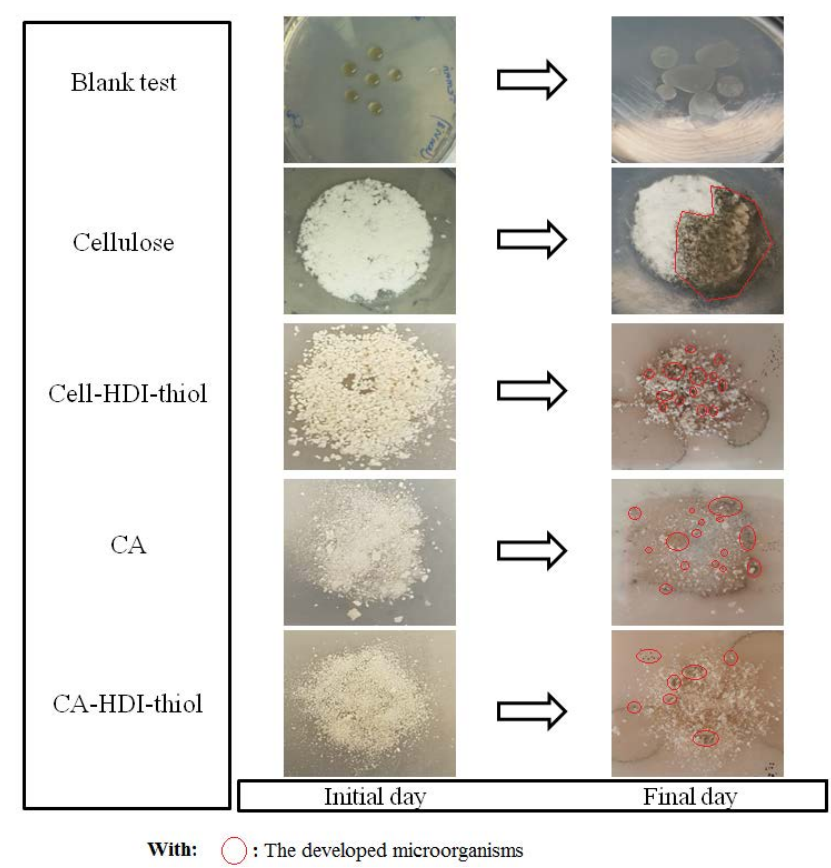

Figure 7: Evolution of the biodegradation process of cellulose, Cell-HDI-thiol, cellulose acetate and CA-HDI-thiol after 28 days of incubation under aerobic solid conditions 
The CrI decreased from $88 \%$ to $85 \%$ for cellulose and its Cell-HDI-thiol derivative, indicating that the content of the amorphous regions has not changed so much. ${ }^{49}$ In addition, this fact indicates that the product does not lose its crystallinity after this modification type. For cellulose acetate and CA-HDI-thiol, respectively, an increase in the crystallinity index was noted, varying from $64 \%$ to $84 \%$. The X-ray diffraction studies showed that crystallinity depends greatly on the structure of the reagents and the reaction conditions. It can be assumed that a new organization of chains and new crystalline domains appeared; probably due to the new hydrogen bonds established between the urethane groups and the oxygen atoms of the cellulose derivatives.

\section{Biodegradation study}

The biodegradation study of cellulose, cellulose acetate, Cell-HDI-thiol and CA-HDIthiol compounds was conducted under aerobic solid and liquid conditions according to ASTM (G21-70, G22-76 and G29-75), AFNOR (X 41-514-81 and X41-517-69), DIN 53739, ISO 846 and ISO 14851. Cellulose, Cell-HDI-thiol, cellulose acetate and CA-HDI-thiol compounds were placed on agar medium in Petri dishes, inoculated with lixivia and incubated at $25^{\circ} \mathrm{C}$ for 28 days.

\section{Biodegradation under aerobic solid conditions}

The aerobic biodegradation experiments in solid conditions were validated by visual assessment (qualitative information) showing the growth process on the surface of the tested biopolymers or clear areas due to the hydrolysis of the substrate by the enzymes released by the microorganisms.

Figure 7 summarizes the evolution of the biodegradation process of the blank, cellulose, Cell-HDI-thiol, cellulose acetate and CA-HDIthiol under aerobic solid conditions. After 28 days of incubation, it could be noted visually that cellulose and its derivatives were largely colonized by the microorganisms associated to the lixivia, composed mainly of fungi; while no microbial growth was observed in the absence of the synthesized biocomposites (blank test). This finding indicates the biodegradation of cellulose and its derivatives by microorganisms, which used them as a sole carbon source for their growth metabolism.
It can be seen that the cellulose acetate, Cell-HDI-thiol and CA-HDI-thiol samples started degrading after 5 days; while the cellulose started degrading after 10 days of incubation, probably due to its high crystallinity level (it is known that the crystalline regions are more difficult to attack by microorganisms), but it can also be due to an error during the preparation of the mixture. This period also depends on several other factors, such as humidity of the medium and the assimilation time of microorganisms. ${ }^{50}$ It can be seen from the photos in Figure 7 that cellulose is attacked more rapidly by microorganisms than the other tested derivatives. These results will be proven by biochemical oxygen demand (BOD) tests.

\section{Biodegradation under aerobic liquid conditions}

The aerobic biodegradation experiments in liquid medium were validated by assessing the biochemical oxygen demand (BOD). The biochemical oxygen demand was determined in a closed respirometer (ISO 14851 (1999)) for 40 days. The biodegradation level was expressed as the amount of $\mathrm{O}_{2}$ consumed during the process $\left(\mathrm{mg} \mathrm{O}_{2} / \mathrm{L}\right)$. The amount of $\mathrm{O}_{2}$ consumed during the biodegradation process (after correction with the blank test) was expressed as a percentage of the theoretical oxygen demand (ThOD). The theoretical oxygen demand was expressed as mass of $\mathrm{O}_{2}$ per mass of polymers, and was determined by calculating the amount of $\mathrm{O}_{2}$ necessary for aerobic mineralization, i.e., complete oxidation of carbon to $\mathrm{CO}_{2}$.

The biodegradation of cellulose, cellulose acetate, Cell-HDI-thiol and CA-HDI-thiol was evaluated by the percentage and rate of biodegradability. It is worth noting that, according to the curves plotted in Figure 8, the slightly variable degradation kinetics generally presents almost the same trend for all the degradation curves. As known, two key steps occur in the polymer biodegradation process: firstly, there is a depolymerization or chain cleavage step, and secondly, there is a mineralization step. The first step normally occurs outside the organism due to the size of the polymeric chain and the insoluble nature of many of the polymers in water medium. Once sufficiently small-size oligomeric or monomeric fragments are formed, they are 
transported into the cell where they are mineralized. ${ }^{51}$

The degradation kinetics for all the curves follows almost the same trend. The results show that, whether the cellulose, cellulose acetate, or their derivatives were used, the consumption of $\mathrm{O}_{2}$ was noted, confirming the multiplication and growth of microorganisms and their ability to use these compounds as a sole carbon source. It is worth noticing that the biodegradation curves of all the polymers are distinguished by a first phase (around 8-10 days), characterized by a low increase in the biodegradation values. This phase may be due to the adaptation of the microorganisms to the new environment, by synthesizing the enzymes necessary for the biodegradation of the new carbon sources, and it may be related to the lag phase of microbial growth. The second phase

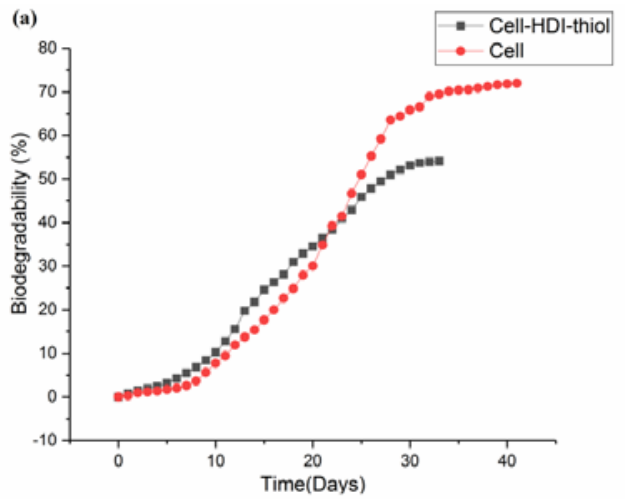

noted on the biodegradation curves is characterized by an exponential increase in the biodegradation percentages for all the synthesized biocomposites. This exponential phase, which may be assigned to the exponential growth phase of microorganisms, indicates a high and quick biodegradation process of the synthesized biocomposites by microorganisms associated to the soil. It is generally modeled by an exponential equation (Eq. 14):

$$
\begin{aligned}
& B D=B D_{0} e^{\mu t} \\
& \ln B D=\mu\left(t-t_{0}\right)+\ln B D_{0}
\end{aligned}
$$

where $\mathrm{BD}_{0}$ represents the biodegradation at $\mathrm{t}_{0}$, $\mathrm{BD}$ represents the biodegradation at $\mathrm{t}$ and $\mu$ represents the rate of biodegradation.

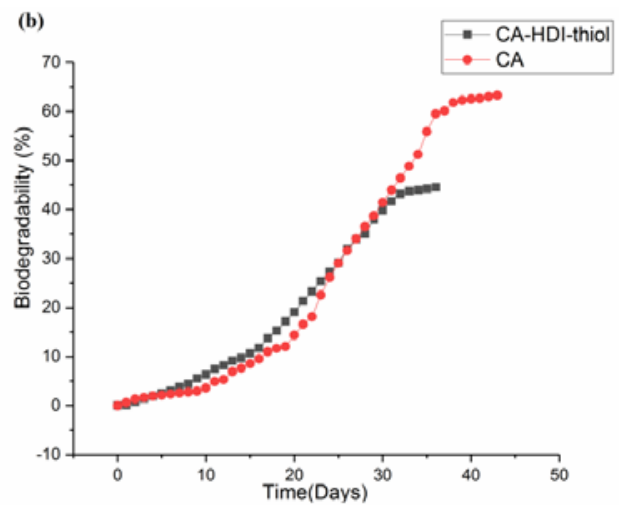

Figure 8: Biodegradation percentage of (a) cellulose and Cell-HDI-thiol, and (b) cellulose acetate and CA-HDIthiol after 40 days of incubation at $25^{\circ} \mathrm{C}$ under aerobic liquid conditions

Table 3

Rate of biodegradation $(\mu)$ of tested biopolymers

\begin{tabular}{lc}
\hline Biopolymer & Rate of biodegradation $(\mu)$ \\
\hline Cellulose & 0.11 \\
Cell-HDI-thiol & 0.14 \\
Cellulose acetate & 0.12 \\
CA-HDI-thiol & 0.10 \\
\hline
\end{tabular}

The literature reported that, after 40 days of incubation, at least $60 \%$ of cellulose is biodegraded in compost. ${ }^{52}$ The results obtained in this work indicated that over $72 \%$ of the cellulose used here is biodegraded after 40 days of incubation. It can be concluded that the cellulose is more degradable in liquid medium than in compost, probably the microorganisms in leachate are more diversified and numerous. Cell-HDI-thiol is biodegraded to over 55\% after 35 days of incubation (Fig. 8a). Indeed, the cellulose acetate is potentially degradable in the environment and the rate of its biodegradation is very influenced by the DS values and, therefore, the rate of crystallinity. ${ }^{53}$ In Figure $8 b$, cellulose acetate (DS $=1.7$ ) is biodegraded to over $62 \%$ after 40 days of incubation and CA-HDI-thiol is biodegraded to over $45 \%$ after 35 days of incubation. The experimental results suggested that the cellulose was more biodegradable than CellHDI-thiol, while the cellulose acetate was more biodegradable than CA-HDI-thiol and CA-HDI-thiol was more biodegradable than 
Cell-HDI-thiol. In conclusion, the compounds having carbamate and thiocarbamate groups grafted on their main chains are more stable and show slow biodegradation probably due to the presence of these groups.

The introduction of ester groups increases the ability of materials to degrade, but the introduction of carbamate and/or thiocarbamate groups acts negatively in the biodegrading process (\%); because the cellulose carbamate and the cellulose acetate carbamate show a biodegradation percentage that does not exceed $55 \%$.

According to Table 3, it can be seen that the rate of biodegradation $(\mu)$ follows the order: cellulose $<$ Cell-HDI-thiol and CA-HDI-thiol $<$ cellulose acetate. Hence, the introduction of the the thiocarbamate group in cellulose increased significantly its biodegradation rate, while the grafting of the thiocarbamate and carbamate groups in cellulose acetate reduced its biodegradation rate. These variations in the biodegradation rate can be explained by the presence of carbamate functions in Cell-HDIthiol derivatives, which are difficult to degrade. However, the reduction in the biodegradation rate for CA-HDI-thiol derivatives, compared with cellulose acetate, can be explained by the introduction of the thiocarbamate and carbamate groups in the cellulose acetate backbone, which are less degradable than the ester groups contained in cellulose acetate. However, the CA-HDI-thiol compound degrades more easily than the cellulose due to the groups attached on its chains (ester, carbamate). Microbial attack can occur by involving esterase enzymes. Fungi associated with biopolymers are known for their esterase production capacity on various plant polysaccharides. ${ }^{54}$ This variation of the biodegradation rate can be also explained by the variation of their crystallinity index (CrI) values. Moreover, it is worth noting that the biodegradation is faster inside the amorphous regions than in the crystalline regions. ${ }^{55}$

It has been already remarked that a positive result in a biodegradation test is a proof that these biopolymers are biodegradable. The rate of degradation in very dependent upon the biodegradation conditions (solid, liquid medium) and especially on the molecular structure of the sample submitted to the biodegradation test, as well as on other parameters, such as crystallinity level, molecular weight, etc.

\section{CONCLUSION}

The synthesis of compounds Cell-HDI-thiol and CA-HDI-thiol holding simultaneously carbamate and thiocarbamate groups from cellulose and cellulose acetate, using a one-pot click reaction in a homogenous system, was reported. This grafting procedure allows fast access to these products with the possibility to control easily their degree of substitution (DS) and the density of the graft. In a first step, a diisocyanate group was reacted with a compound possessing a thiol function to prepare a precursor having a free isocyanate group. In a second step, the resulted product was reacted again with cellulose or cellulose acetate by an additional reaction using DBTL as a catalyst. This modification avoids toxic and expensive solvents and reagents. The FTIR, NMR, XDR and TGA/DTG techniques were used for the characterization of the obtained products and the results showed that this modification method was successful.

The Flory-Huggins interaction parameter values $\left(\chi_{\mathrm{sp}}\right)$, solubility parameters and the solubility tests of the thiocarbamate compounds were determined, showing better solubility in comparison with the materials emerged from raw resources. Thus, our findings can open the way to a wide range of applications for these materials in different industrial fields, such as biofilms, bioplastics for food packaging, amphiphile molecules and biocomposites. The cellulose, cellulose acetate and their derivatives were assessed in biodegradation tests, following two procedures in liquid medium and solid conditions at $25^{\circ} \mathrm{C}$, according to ASTM, AFNOR and ISO standards. The results showed that the lixivia and soil used as inoculums have a remarkable biodegradation effect, and those obtained by the biochemical oxygen demand method are mostly in agreement with the outcome of the microbial growth method. The biodegradation rate was determined for the different derivatives and its various values were interpreted. 
ACKNOWLEDGEMENT: The authors are grateful to Morocco CNRST - Program PPR/2015/17 - (Rabat) for the support to carry out this work and the laboratory associated contract.

\section{REFERENCES}

1 F. Fu, M. Xu, H. Wang, Y. Wang, H. Ge et al., ACS Sustain. Chem. Eng., 3, 1510 (2015), https://doi.org/10.1021/acssuschemeng.5b00219 2 M. Ibrahim and H. Mondal, "Cellulose and Cellulose Composites”, Nova Science Publishers, Inc., New York, 2015, https://doi.org/10.1017/CBO9781107415324.004

3 S. Keshipour and A. Maleki, in "CelluloseBased Superabsorbent Hydrogels”, edited by M. Mondal, Springer, 2019, p. 435, https://doi.org/10.1007/978-3-319-77830-3_17

4 O. Paquet, M. Krouit, J. Bras, W. Thielemans and M. N. Belgacem, Acta Mater., 58, 792 (2010), https://doi.org/10.1016/j.actamat.2009.09.057

5 M.-E. Fei, T. Xie, W. Liu, H. Chen and R. Qiu, Cellulose, 24, $5505 \quad$ (2017), https://doi.org/10.1007/s10570-017-1497-1

6 G. Yu, Y. Teng, W. Lai and C. Yin, Int. J. Biol. Macromol., 93, $1155 \quad$ (2016), https://doi.org/10.1016/j.ijbiomac.2016.09.081

$7 \quad$ X. Fan, Z. W. Liu, J. Lu and Z. T. Liu, Ind. Eng. Chem. Res., 48, $6212 \quad$ (2009), https://doi.org/10.1021/ie801703x

8 S. T. Fujiwara, K. Ribeiro and T. M. de Andrade, Environ. Technol., 37, 1664 (2016), https://doi.org/10.1080/09593330.2015.1127290

9 D. H. N. Perera, S. K. Nataraj, N. M. Thomson, A. Sepe, S. Hüttner et al., J. Membane Sci., 453, 212

(2014),

https://doi.org/10.1016/j.memsci.2013.10.062

10 P. Fei, L. Liao, B. Cheng and J. Song, Anal. Methods, $\quad 9, \quad 6194 \quad$ (2017), https://doi.org/10.1039/C7AY02165H

11 J. Chen, J. Xu, K. Wang, X. Cao and R. Sun, Carbohyd. Polym., 137, $685 \quad$ (2016), https://doi.org/10.1016/j.carbpol.2015.11.034

12 A. M. Das, A. A. Ali and M. P. Hazarika, Carbohyd. Polym., 112, $342 \quad$ (2014), https://doi.org/10.1016/j.carbpol.2014.06.006

13 A. M. Senna, K. Monteiro and V. R. Botaro, Carbohyd. Polym., 114, $260 \quad$ (2014), https://doi.org/10.1016/j.carbpol.2014.08.017

14 S. Fischer, K. Thümmler, B. Volkert, K. Hettrich, I. Schmidt et al., Macromol. Symp., 262, 89 (2008), https://doi.org/10.1002/masy.200850210 15 H.-K. Kim and A. Lee, Tetrahedron Lett., 57, 4890 (2016), https://doi.org/10.1039/C6OB01290F 16 L. Yao, Y. Lu, Y. Wang and L. Hu, Carbon N. $\begin{array}{llll}Y ., & 69, & 552 & \text { (2014), }\end{array}$ https://doi.org/10.1016/j.carbon.2013.12.066 17 S. Gan, S. Zakaria, C. H. Chia, H. Kaco and F. N. M. Padzil, Carbohyd. Polym., 106, 160 (2014), https://doi.org/10.1016/j.carbpol.2014.01.076 18 C. Yin, J. Li, Q. Xu, Q. Peng, Y. Liu et al., Carbohyd. Polym., 67, $147 \quad$ (2007), https://doi.org/10.1016/j.carbpol.2006.05.010 19 C. Yin and X. Shen, Eur. Polym. J., 43, 2111 (2007),

https://doi.org/10.1016/j.eurpolymj.2007.01.041

20 Z. Cheng, Y. Liu, D. Zhang, C. Lu, C. Wang et al., Int. J. Biol. Macromol., 131, 387 (2019), https://doi.org/10.1016/j.ijbiomac.2019.02.161

21 S. El Barkany, A. El Idrissi, C. Zanagui, I. Jilal, F. Tabaght et al., J. Mater. Environ. Sci., 8, 1195 (2017), http://www.jmaterenvironsci.com/

22 X. Qiu, S. Tao, X. Ren and S. Hu, Carbohyd. Polym., $\quad 88, \quad 1272 \quad$ (2012), https://doi.org/10.1016/j.carbpol.2012.02.007

23 S. Gan, S. H. Piao, H. J. Choi, S. Zakaria and C. H. Chia, Carbohyd. Polym., 137, 693 (2016), https://doi.org/10.1016/j.carbpol.2015.11.035

24 S. T. Vallejos, M. F. Erben, O. E. Piro, E. E. Castellano and C. O. Della Védova, Polyhedron, 28, 937

(2009), https://doi.org/10.1016/j.poly.2009.01.022

25 Z. A. Nagieb and A. A. El-Gammal, J. Appl. Polym. Sci., 31, $179 \quad$ (1986), https://doi.org/10.1002/app.1986.070310116

26 D. N.-S. Hon, in "Materials and Chemicals from Biomass", edited by R. Rowell, ACS Symposium Series, 1992, p. 176, https://doi.org/10.1021/bk1992-0476.ch012

27 A. S. Amarasekara and O. S. Owereh, Carbohyd. Polym., 78, $635 \quad$ (2009), https://doi.org/10.1016/j.carbpol.2009.05.032

${ }_{28}$ Y. Song, J. Zhou, L. Zhang and X. Wu, Carbohyd. Polym., 73, 18 (2008), https://doi.org/10.1016/j.carbpol.2007.10.018

29 A. El Idrissi, S. El Barkany, H. Amhamdi and A. K. Maaroufi, J. Appl. Polym. Sci., 128, 537 (2013), https://doi.org/10.1002/app.37500

30 S. Doyle and R. A. Pethrick, J. Appl. Polym. Sci., 33, $95 \quad$ (1987), https://doi.org/10.1002/app.1987.070330109

31 R. F. Fedors, Polym. Eng. Sci., 14, 147 (1974), https://doi.org/10.1002/pen.760140211

32 C. M. Hansen, "Hansen Solubility Parameters", second ed., Taylor and Francis Group, 2007, https://doi.org/10.1017/CBO9781107415324.004

33 D. W. Van Krevelen and K. Te Nijenhuis, "Properties of Polymers", Elsevier, fourth ed., 2009, https://www.elsevier.com/books/propertiesof-polymers/van-krevelen/978-0-08-054819-7

34 T. Lindvig, M. L. Michelsen and G. M. Kontogeorgis, Fluid Phase Equilib., 203, 247 (2002), https://doi.org/10.1016/S03783812(02)00184-X

35 A. Calmon-Decriaud, V. Bellon-Maurel and F. Silvestre, Adv. Polym. Sci., 135, 207 (1998), https://doi.org/10.1007/3-540-69191-X_3

36 A. Krzan, S. Hemjinda, S. Miertus, A. Corti and E. Chiellini, Polym. Degrad. Stabil., 91, 2819 
(2006),

https://doi.org/10.1016/j.polymdegradstab.2006.04. 034

37 V. Mezzanotte, R. Bertani, F. D. Innocenti and M. Tosin, Polym. Degrad. Stabil., 87, 51 (2005), https://doi.org/10.1016/j.polymdegradstab.2004.06. 009

38 I. Moura, A. V Machado, F. M. Duarte and R. Nogueira, J. Appl. Polym. Sci., 119, 3338 (2011), https://doi.org/10.1002/app.32966

39 L. M. Wu, D. S. Tong, L. Z. Zhao, W. H. Yu, C. H. Zhou et al., Appl. Clay Sci., 95, 74 (2014), https://doi.org/10.1016/j.clay.2014.03.014

40 Y. Guo, J. Zhou, Y. Song and L. Zhang, Macromol. Rapid Commun., 30, 1504 (2009), https://doi.org/10.1002/marc.200900238

${ }^{41}$ H. S. Barud, A. M. de Araújo Júnior, D. B. Santos, R. M. N. de Assunção, C. S. Meireles et al., Thermochim. Acta, 471, 61 (2008), https://doi.org/10.1016/j.tca.2008.02.009

42 P. Jandura, B. V. Kokta and B. Riedl, J. Appl. Polym. Sci., 78, $1354 \quad$ (2000), https://doi.org/10.1002/1097-

4628(20001114)78:7<1354::AID-

APP60>3.0.CO;2-V

43 S. El Barkany, A. El Idrissi, C. Zannagui, F. Tabaght, A.-K. Maaroufi et al., Moroccan J. Chem., 4, 4016), https://revues.imist.ma/index.php?journal=morjche m\&page $=$ article\&op=view\&path\%5B\%5D=5265

44 Suhas, V. K. Gupta, P. J. M. Carrott, R. Singh, M. Chaudhary et al., Bioresour. Technol., 216, 1066

(2016), https://doi.org/10.1016/j.biortech.2016.05.106

45 B. Lindman, G. Karlström and L. Stigsson, J. Mol. Liq., 156, $76 \quad$ (2010), https://doi.org/10.1016/j.molliq.2010.04.016
46 W. Hu, S. Chen, Q. $\mathrm{Xu}$ and H. Wang, Carbohyd. Polym., 83, $1575 \quad$ (2011), https://doi.org/10.1016/j.carbpol.2010.10.016

47 G. R. Filho, S. F. da Cruz, D. Pasquini, D. A. Cerqueira, V. de S. Prado et al., J. Membane Sci., 177, 225 (2000), https://doi.org/10.1016/S03767388(00)00469-5

48 A. Ben Mabrouk, H. Kaddami, S. Boufi, F. Erchiqui and A. Dufresne, Cellulose, 19, 843 (2012), https://doi.org/10.1007/s10570-012-9662-z

49 A. El Idrissi, S. El Barkany, H. Amhamdi and A. K. Maaroufi, J. Appl. Polym. Sci., 127, 3633 (2013), https://doi.org/10.1002/app.37982

50 A. Benarbia, A. Elidrissi, R. Bellaouchi and A. Asehraou, Int. J. Eng. Tech. Res., 3, 348 (2015), https://www.researchgate.net/publication/28997684 4_Polybutylene_succinate_preparation_and_Biodeg radation_study_of_cellulose_and_cellulose_blends 51 M. Van Der Zee, in "Biodegradable Polymers: Synthesis, Characterization and Applications”, edited by A. Lendlein and A. Sisson, Wiley-VCH, first ed., 2011, p. 263, https://doi.org/10.1002/9783527635818.ch11

52 M. Funabashi, F. Ninomiya and M. Kunioka, Int. J. Mol. Sci., 10, 3635 (2009), https://doi.org/10.3390/ijms10083635

53 C. M. Buchanan, R. M. Gardner and R. Komarek, J. Appl. Polym. Sci., 47, 1709 (1993), https://doi.org/10.1002/app.1993.070471001

54 P. Biely, Biotechnol. Adv., 30, 1575 (2012), https://doi.org/10.1016/j.biotechadv.2012.04.010

55 N. Jiang, L. Zhao and Z. Gan, Polym. Degrad. Stabil., $\quad 95, \quad 1045 \quad$ (2010), https://doi.org/10.1016/j.polymdegradstab.2010.03. 004 